\title{
Humidity Detection Using Metal Organic Framework Coated on QCM
}

\author{
Lakshmoji Kosuru, Adam Bouchaala, Nizar Jaber, and Mohammad I. Younis \\ Physical Sciences and Engineering Division, King Abdullah University of Science and Technology, Thuwal 23955-6900, Saudi Arabia
}

Correspondence should be addressed to Mohammad I. Younis; mohammad.younis@kaust.edu.sa

Received 15 May 2016; Accepted 28 June 2016

Academic Editor: Daniel Matatagui

Copyright (C) 2016 Lakshmoji Kosuru et al. This is an open access article distributed under the Creative Commons Attribution License, which permits unrestricted use, distribution, and reproduction in any medium, provided the original work is properly cited.

Quartz crystal microbalance (QCM) coated with poly-4-vinylpyridine (PVP) and metal organic framework HKUST-1 are investigated and compared for humidity sensing. Drop casting method is employed to coat the PVP and HKUST-1 solutions onto the surface of a quartz crystal microbalance. The resonance frequencies of these sensors with varying relative humidity (RH) from $22 \% \mathrm{RH}$ to $69 \% \mathrm{RH}$ are measured using impedance analysis method. The sensitivity, humidity hysteresis, response, and recovery times of these sensors are studied. The sensitivities of uncoated, PVP, and HKUST-1 coated QCM sensors are $7 \mathrm{~Hz}, 48 \mathrm{~Hz}$, and $720 \mathrm{~Hz}$, respectively, in the range of $22 \% \mathrm{RH}-69 \% \mathrm{RH}$. The extraction of desorption rate and adsorption energy associated with the adsorption and desorption of water molecules on these surfaces reveals that HKUST-1 has better sensing properties than PVP and uncoated QCM sensors. In this work, the HKUST-1 coated QCM is shown to be a promising material for moisture detection.

\section{Introduction}

Humidity measurements play a crucial role in various fields, such as industries, agriculture, automobiles, and medical and other domestic applications for human comfort [1-3]. Thus, there is a demand for affordable and highly sensitive humidity sensors. Quartz crystal microbalance (QCM) is best suitable for this requisite since it is highly sensitive to mass changes [4-6]. QCM has been widely used as a mass sensor by measuring the shift in resonance frequency due to mass loading [4-9]. The change in mass $(\Delta m)$ of the QCM can be estimated by measuring the shift in the resonance frequency $(\Delta f)$ and is given by Sauerbrey equation $[9,10]$ :

$$
\Delta f=-\left(\frac{2 f_{0}^{2}}{a \sqrt{\rho_{q} \mu_{q}}}\right) \Delta m,
$$

where $f_{0}(\mathrm{~Hz})$ is the resonance frequency of the $\mathrm{QCM}, \rho_{q}$ is the density of quartz crystal $\left(2.649 \mathrm{~g} \mathrm{~cm}^{-3}\right), \mu_{q}$ is the shear modulus $\left(2.947 \times 10^{10} \mathrm{~N} / \mathrm{m}^{2}\right)$, and $a$ is the area of the gold electrode onto the quartz crystal.

QCM is extensively studied as a gas sensor [11-15]. In the gas sensing applications, studies mainly focused on improving the sensitivity or enhancing the sensing properties like reproducibility and response/recovery speed of the materials. These properties depend on the chemical and physical properties of the sensing film on the QCM based sensors. Various materials, such as organic polymers [16], ceramics [15], hybrid polymer/inorganics systems, polymer electrolytes [17], and composites [18], are used for humidity sensing.

Recently, metal organic frameworks (MOFs) have drawn attention due to their structural and functional tunability [1924]. They are a new class of crystalline nanoporous materials made by linking inorganic and organic units by strong bonds. The significant porosity has allowed the inclusion of large molecules and their high surface area makes them suitable for different sensing applications. MOF-based humidity sensors are reported by employing different analysis techniques such as luminescence spectroscopy, surface plasmon resonance spectroscopy, surface acoustic wave, QCM, and localized surface polarized resonance (LSPR) [25-27]. Different MOF thick film pastes are screen-printed on top of the interdigitated electrodes and used for sensing the concentration of $\mathrm{O}_{2}, \mathrm{CO}_{2}, \mathrm{C}_{3} \mathrm{H}_{8}, \mathrm{NO}, \mathrm{H}_{2}$, ethanol, and methanol in the gas atmosphere and under different test gas humidity 


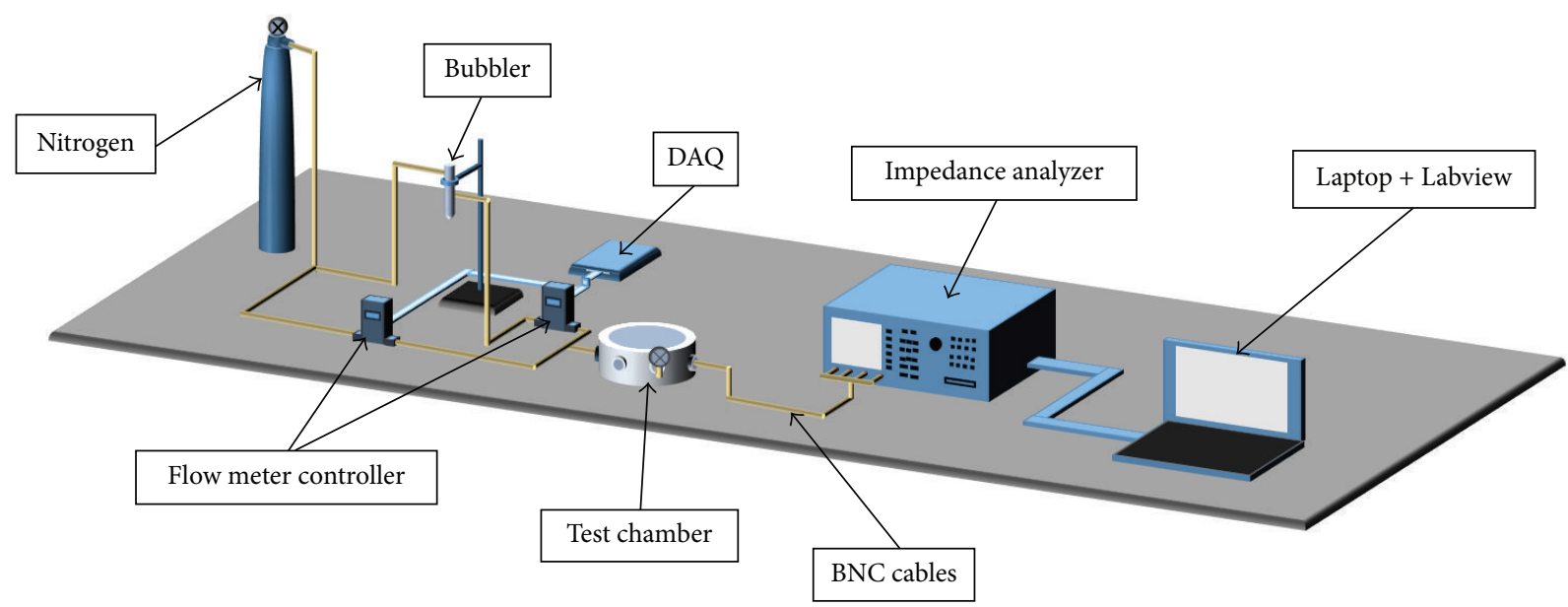

Figure 1: 3D diagram of the experimental setup used for relative humidity detection.

conditions as impedimetric gas sensor [28]. The copper (II) $\mathrm{MOF}\left[\mathrm{Cu}_{3}(\mathrm{btc})_{2}\right](\mathrm{btc}=1,3,5$-benzenetricarboxylate), a metal organic framework also known as HKUST-1, integrating with QCM, was first time investigated for detection of volatile organic compounds, such as acetone, tetrahydrofuran (THF), and isopropyl alcohol (IPA) [29]. Allendorf et al. [30] used microcantilever coated with HKUST-1 to detect the water, methanol, and ethanol vapors. Ellern et al. used piezoelectric microcantilever coated with HKUST-1 for humidity and hydrocarbon gases detection [31].

In this work, we study the performances of a QCM coated with HKUST-1 and PVP for relative humidity sensing. Different sensing properties of these sensors, such as sensitivity, repeatability, response, and recovery times, are investigated.

\section{Experiment}

2.1. Preparation of PVP and HKUST-1. Polyvinyl pyridine (PVP) solution is prepared by dissolving $1 \mathrm{mg}$ PVP powder with a molecular weight of 8,000 in $10 \mathrm{~mL}$ of ethanol. Uniform solution of PVP is achieved by sonicating the mixture for half an hour.

HKUST-1 is prepared by chemical route method [32-34]. $1 \mathrm{mg}$ of HKUST-1 is dissolved in $10 \mathrm{~mL}$ of ethanol and then sonicated for half an hour.

2.2. Fabrication of PVP/HKUST-1 Coated QCM Sensor. A $1.84 \mathrm{MHz}$ AT-cut quartz crystal with $5 \mathrm{~mm}$ diameter gold electrodes is used in this work. The QCM is thoroughly washed with deionized (DI) water and then with the ethanol solution. It is dried for one hour at $50^{\circ} \mathrm{C}$. Drop casting method is used to deposit the polymer and HKUST-1 solutions onto the QCM surface. After deposition of these sensing materials on QCM, it is dried for one hour at $50^{\circ} \mathrm{C}$ and kept in a dry environment overnight.

2.3. Apparatus. Figure 1 shows the experimental setup used in this work. QCM sensor is placed in a customized test chamber. A high-pressure nitrogen supply is connected to a bubbler, which contains the desired gas in the liquid phase.
The output of the bubbler is connected to the test chamber via the flow controller. A data acquisition card (DAQ) from National Instruments is connected to the flow controller and set to allow the vapor flow. Experiments are conducted by varying the relative humidity $(\mathrm{RH})$ in the chamber. The $\mathrm{RH}$ in the chamber is decreased from $68 \% \mathrm{RH}$ to $6 \% \mathrm{RH}$ by purging nitrogen $\left(\mathrm{N}_{2}\right)$ gas over a period of 2 hours. For increasing the $\mathrm{RH}$ from $6 \% \mathrm{RH}$ to $68 \% \mathrm{RH}$, the chamber is purged with $\mathrm{N}_{2}$ gas through DI water. A standard RH meter is used to measure the $\mathrm{RH}$ in the chamber. The resonance frequency of the QCM at different RH levels is measured using a precision impedance analyzer. All measurements are conducted at room temperature $\left(25^{\circ} \mathrm{C}\right)$.

\section{Results and Discussion}

Figure 2 shows the conductance curves of the uncoated, PVP, and HKUST-1 coated QCM sensors at 68\% RH and $22 \% \mathrm{RH}$, respectively. It can be seen that the conductance curves of the three sensors shift to a lower frequency with increasing humidity. It indicates that the mass loading due to adsorption of water molecules causes a decrease in the resonance frequency of the sensor. The shift in frequency is found to be higher for HKUST-1 coated QCM as compared to others.

Figure 3(a) shows the shift in the frequencies of uncoated, PVP, and HKUST-1 coated QCM sensors with varying RH from $22 \% \mathrm{RH}$ to $68 \% \mathrm{RH}$. The downshift in frequency is due to the addition of mass loading on the sensor as $\mathrm{RH}$ is increased to $68 \% \mathrm{RH}$. The frequency shifts (i.e., sensitivity) of the uncoated, PVP, and HKUST-1 coated QCM humidity sensors are $6.7 \mathrm{~Hz}, 48 \mathrm{~Hz}$, and $720 \mathrm{~Hz}$, respectively, when $\mathrm{RH}$ is changed from $22 \% \mathrm{RH}$ to $68 \% \mathrm{RH}$ in the chamber. The sensitivity of the HKUST-1 coated QCM is two orders of magnitude higher than the uncoated QCM and one order of magnitude higher than the PVP coated QCM humidity sensor, respectively. Large porosity and intrinsic hydrophilicity of HKUST-1 material enable more adsorption sites for sensing and hence resulted in higher frequency shift than other materials. 


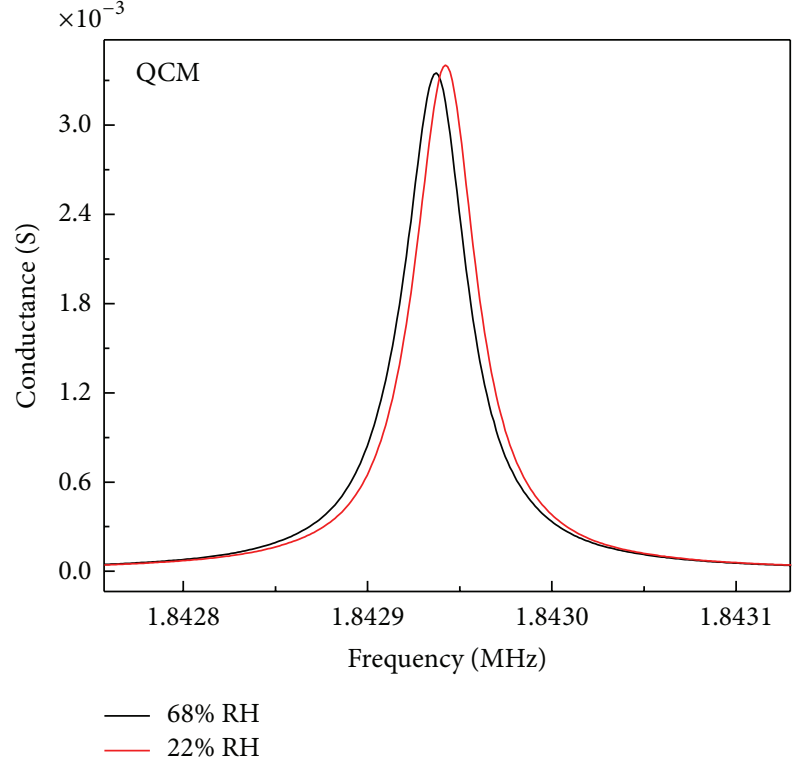

(a)

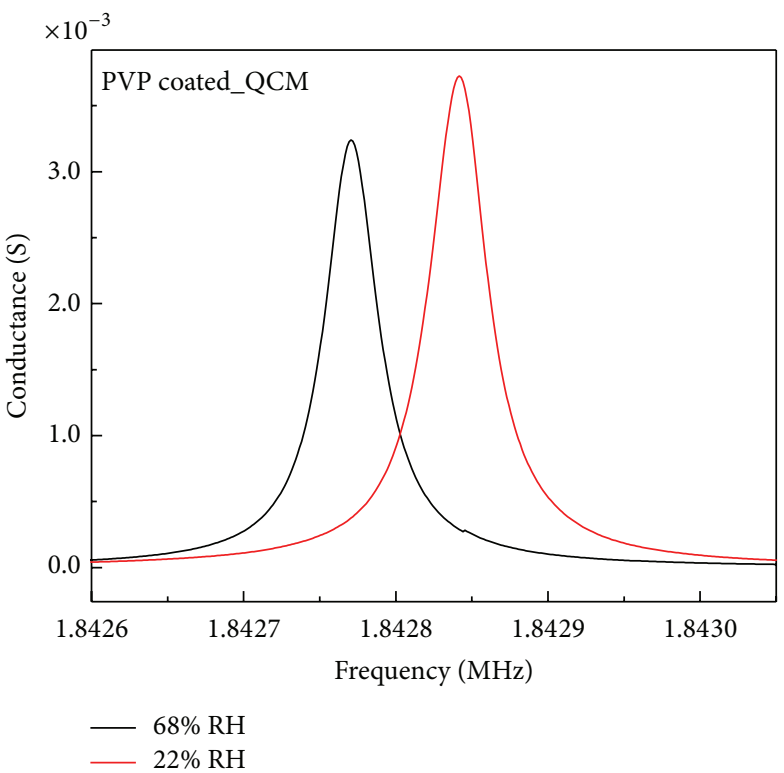

(b)

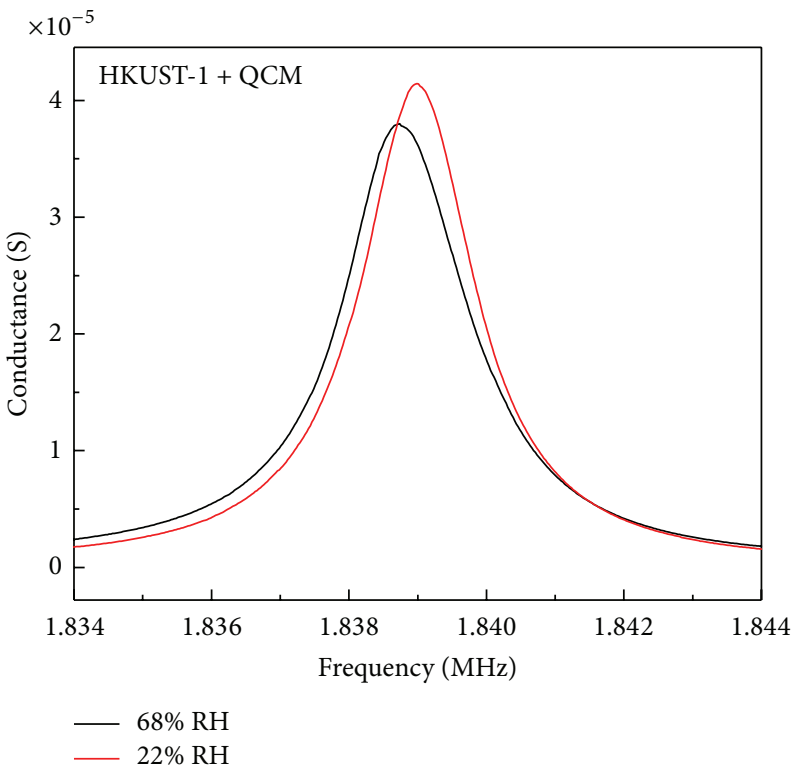

(c)

FIgURE 2: The conductance curves of (a) uncoated, (b) PVP, and (c) HKUST-1 coated QCM at 68\% RH and 22\% RH values.

Logarithm of the frequency shift of all the devices shows linear relationship with the relative humidity. Figure $3(\mathrm{~b})$ shows $\log (\Delta f)$ with relative humidity for the three devices. The regression coefficients, $R^{2}$, obtained by linearly fitting the data, are estimated as $0.03859,0.01003$, and 0.01003 for uncoated, PVP, and HKUST-1 coated QCM humidity sensors, respectively.

Hysteresis is defined as the lag in the response exhibited by a sensor when exposed to adsorption and desorption process. For a perfect sensor, the adsorption and desorption curves typically follow the same path. The humidity hysteresis characteristics of the three devices are also examined. During the adsorption process, the devices are exposed to $\mathrm{RH}$ in the chamber from $22 \% \mathrm{RH}$ to $68 \% \mathrm{RH}$. During the desorption process, the RH in the chamber is decreased from $68 \%$ to $22 \%$ RH. Figure 4 shows the hysteresis response of the three devices for increasing and decreasing of relative humidity in the chamber. The lag in the response of the three devices during adsorption and desorption of water molecules is clearly observed.

All the devices show hysteresis in the response curves when the RH is increasing and decreasing in the chamber. The rate of adsorption is not the same as the rate of desorption in all the devices. At 22\% RH, the hysteresis for HKUST-1 coated 


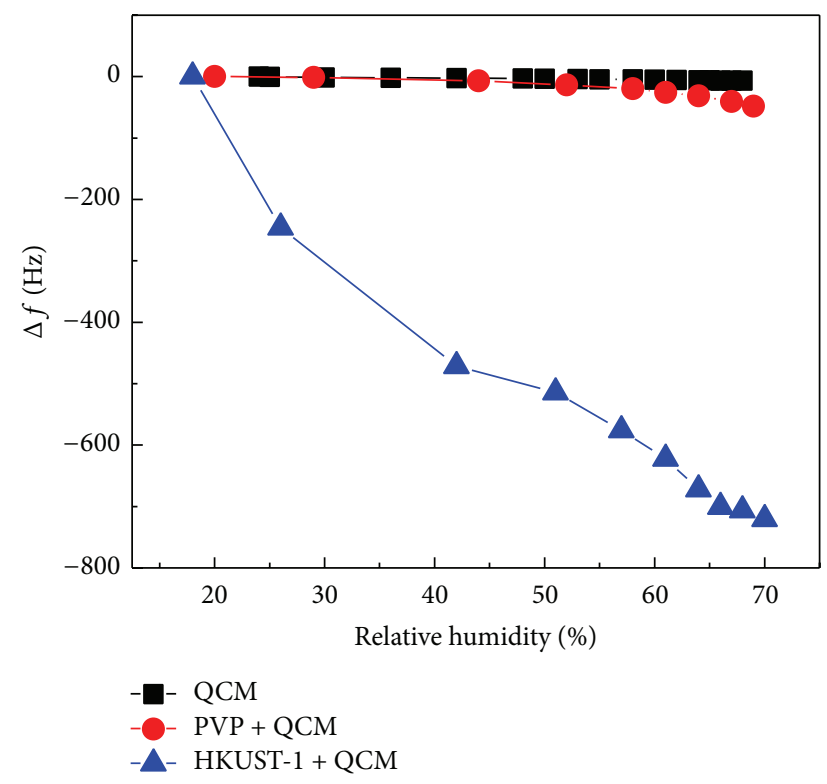

(a)

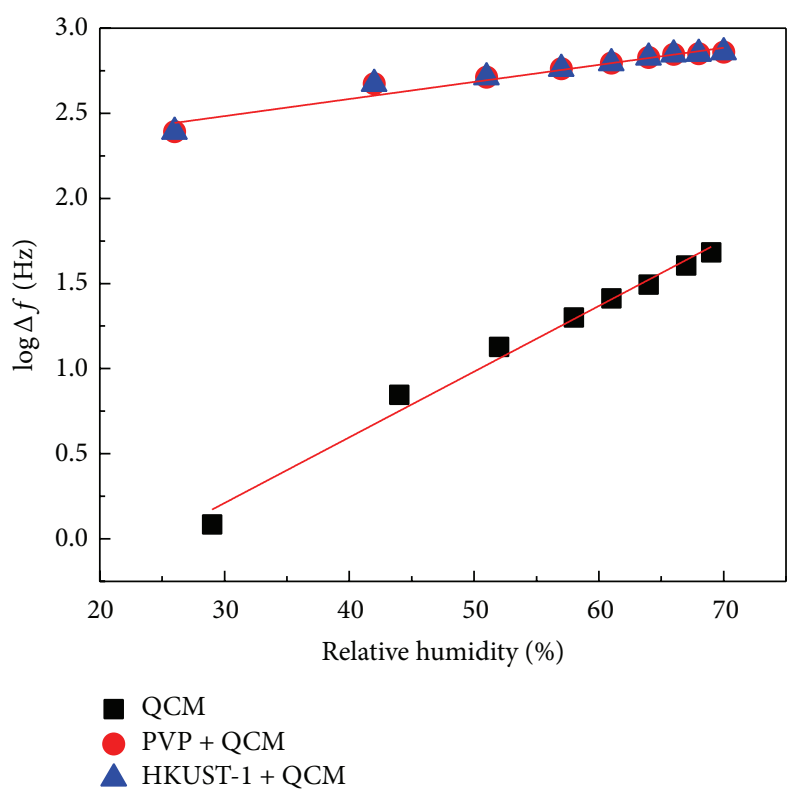

(b)

FIGURE 3: (a) Shift in the frequencies of uncoated, PVP, and HKUST-1 coated QCM with varying relative humidity. (b) The $\log (\Delta f)$ versus relative humidity for all the devices. The data are linearly fitted.

QCM is higher than the other sensors. The reason may be attributed to different energies associated with the adsorption and desorption of water molecules due to the chemical nature of metalorganic framework HKUST-1.

Reproducibility and reversibility are considered to be important properties of any sensor. To study this, the three devices are exposed to different $\mathrm{RH}$ levels in the chamber and repeated for five-time cycles. Figure 5 shows the frequency shift of the three devices when $\mathrm{RH}$ is varied from $22 \% \mathrm{RH}$ to $69 \% \mathrm{RH}$ in the chamber. In the first stage, the chamber is flushed with $\mathrm{N}_{2}$ to attain a base line. Then the sensors are exposed to water vapor flow in the chamber until it reaches $69 \% \mathrm{RH}$ in the chamber. The frequency shift at this $\mathrm{RH}$ has indicated that the maximum amount of water was adsorbed onto the surface. Now water vapor flow is replaced by an $\mathrm{N}_{2}$ flow which reduces the $\mathrm{RH}$ in the chamber from $69 \% \mathrm{RH}$ to $22 \% \mathrm{RH}$ and the whole process is repeated for five cycles. The frequency shift for HKUST-1 coated QCM sensor is higher than PVP and uncoated QCM sensors. However, HKUST1 coated QCM shows more reduced sensing reproducibility than others, which can be due to the high desorption energy required to recover the water molecules from the HKUST-1 film. The other reason may be due to the nonuniform nature of the film coated on QCM due to the drop casting method. On the other hand, the uncoated and PVP coated QCM sensors show good reproducibility in sensing responses. The reproducibility in HKUST-1 coated QCM may be improved by a uniform coating of the film on the QCM.

Response and recovery times are helpful in understanding how fast the adsorption and desorption are taking place on the sensing surface. The frequency shifts versus time for the three sensors for one cycle of low-high-low (22\% RH$68 \% \mathrm{RH}-22 \% \mathrm{RH}$ ) are repeated. Figure 6 shows the frequency shift of PVP and HKUST-1 coated QCM sensor when RH is changed from $22 \% \mathrm{RH}$ to $68 \% \mathrm{RH}$ to $22 \% \mathrm{RH}$.

The time taken to reach $90 \%$ variation in the frequency shift upon exposure to water vapor is defined as the response time $t_{\text {response. }}$ Similarly, the time taken to reach $90 \%$ variation in the frequency shift upon exposure to $\mathrm{N}_{2}$ flow in the chamber is defined as the recovery time $t_{\text {recovery. }}$. The response and recovery times for the sensors are calculated from Figure 6. $t_{\text {response }}$ and $t_{\text {recovery }}$ values for PVP and HKUST1 coated QCM are $116 \mathrm{~s}$ and $386 \mathrm{~s}$ and $1676 \mathrm{~s}$ and $1051 \mathrm{~s}$, respectively. The response times are relatively shorter than the recovery times which implies that the adsorption of water molecules is faster than desorption of water for these sensors.

To understand the physical and chemical mechanisms involved in the adsorption of water molecules on the sensing surfaces, kinetic parameters associated with the molecular adsorption, such as adsorption/desorption rate constant $\left(k_{a}\right.$, $k_{d}$ ), fractional surface coverage $(\theta)$, and the number of adsorption sites $\left(N^{\prime}\right)$, are estimated from the experimental data. The adsorption of molecules on the sensing surface can be understood from its physical chemistry theories of adsorption [35, 36]. Understanding the molecule interaction mechanism allows the designing of appropriate sensing materials for different applications. Kinetic parameters are desirable as high as possible, which bring fast adsorption and desorption rates and high sensitivity of the sensors.

One cycle of adsorption and desorption curves of uncoated, PVP, and HKUST-1 coated QCM sensors from Figure 5 are fitted with a linear fit. Figure 7 shows that the one cycle of adsorption and desorption of water molecules of uncoated QCM and the initial adsorption and desorption are linearly fitted. According to the frequency shift value and using (1), the mass loading due to adsorption can be 


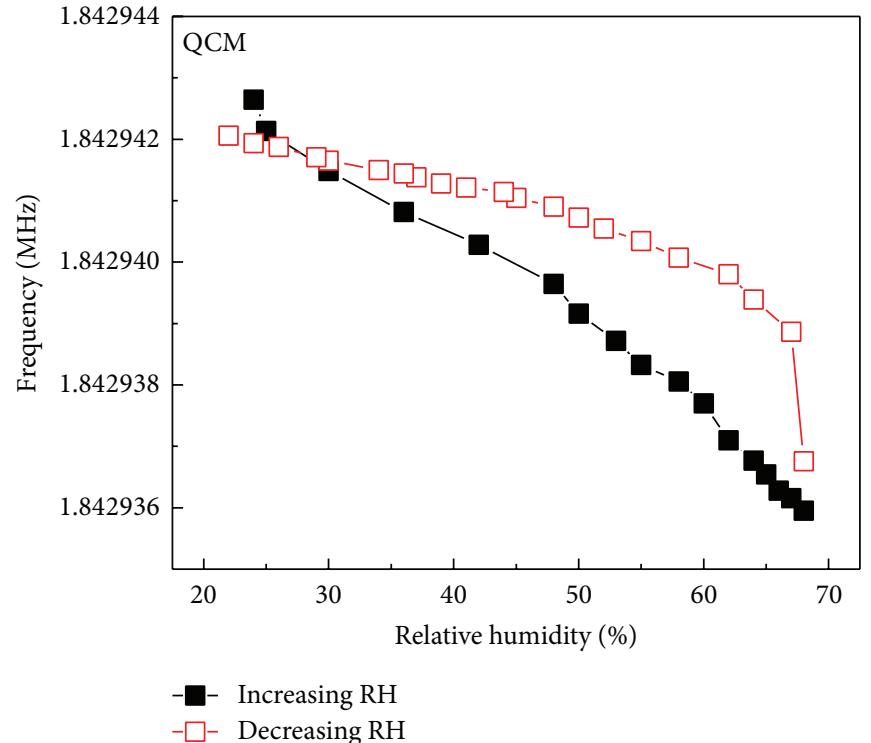

(a)

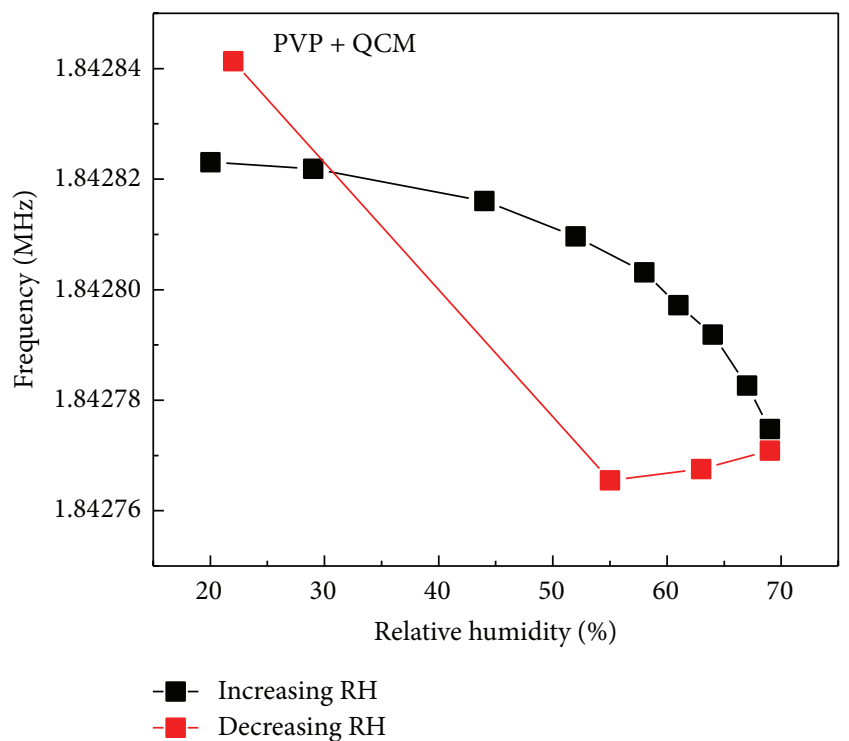

(b)

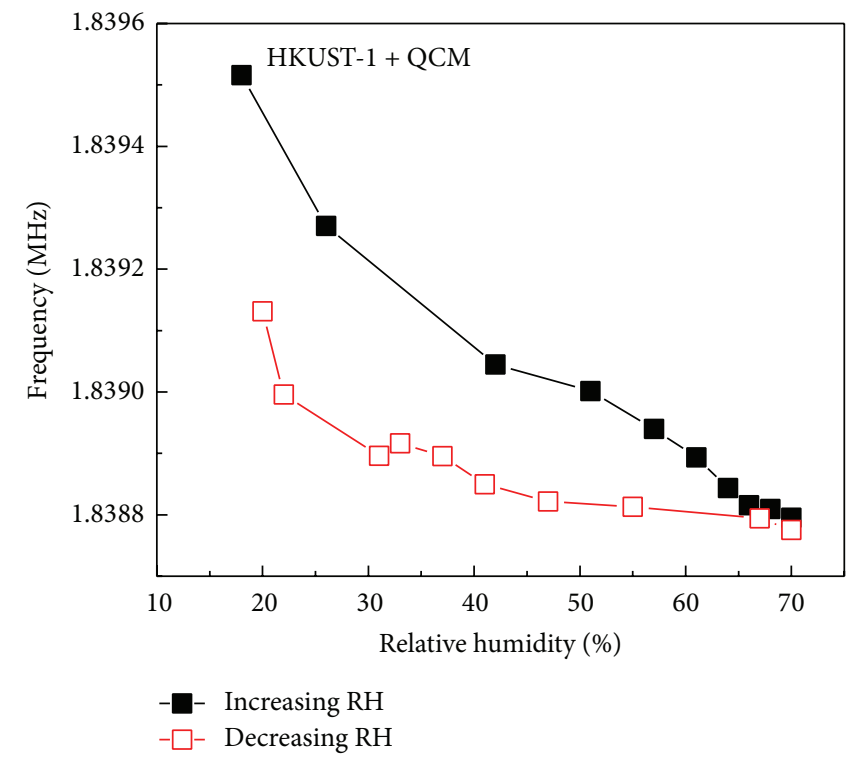

(c)

FIGURE 4: Hysteresis curves of (a) uncoated, (b) PVP, and (c) HKUST-1 coated QCM sensors for increasing and decreasing relative humidity.

estimated. The molar number of the adsorbed molecules $\theta N$ is found to be $1.46 \times 10^{16}$. Putting this $\theta N$ value in the linearly fitted equation of desorption curve as shown in Figure 7 and converting the frequency $(\mathrm{Hz})$ into a molar number of desorbed molecules, the rate of desorption can be obtained. Desorption rate constant is calculated as $k_{d}=4.5 \times 10^{-3} \mathrm{~s}^{-1}$. Now dividing the linear fitted equations of adsorption and desorption curves, we can get the following equations of $\theta=$ $(16 K p) / 11$ and $\theta=K p(1+K p)^{-1}$, where $K=k_{a} / k_{d}, K$ is the rate constant, and $p$ is the partial pressure of the water vapor. Solving these two equations, we get $\theta=43 \%$. From the desorption rate $k_{d}$, adsorption energy can be estimated using [37] $k_{d}=A \exp \left[-E_{a} / N k T\right]$, where $E_{a}$ is the adsorption energy, $N$ is Avogadro's number $\left(6.02 \times 10^{23} \mathrm{~mol}^{-1}\right), k$ is Boltzmann's constant $\left(1.38 \times 10^{-23} \mathrm{JK}^{-1}\right), T$ is the temperature $(293 \mathrm{~K})$, and $A$ is the preexponential factor of the order of $10^{12} \mathrm{~s}^{-1}$. By substituting these values, the activation energy is estimated to be $80 \mathrm{~kJ} / \mathrm{mol}$. Similarly, the same procedure is implemented for PVP and HKUST-1 coated QCM sensor data to extract the kinetic parameters. The sensing parameters and kinetic parameters for all the devices are tabulated in Table 1. It shows that HKUST-1 coated QCM has high sensitivity because of its high adsorption energy and fractional coverage of the molecules on the surface. The sensing parameters may be further improved by a uniform coating of HKUST-1 on QCM. 

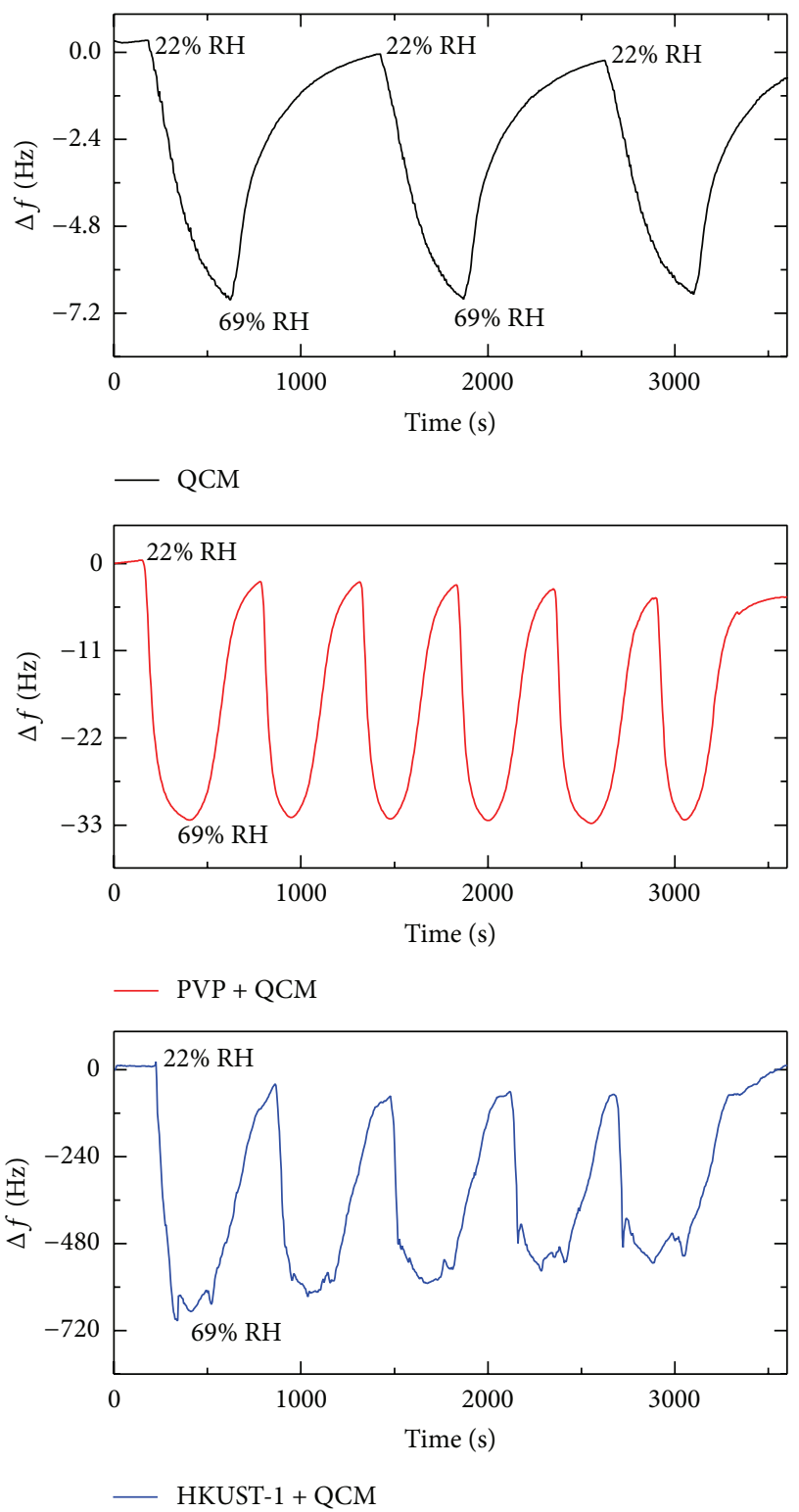

FIgURE 5: Frequency shift of uncoated, PVP, and HKUST-1 coated QCM sensors for varying relative humidity from $22 \% \mathrm{RH}$ to $69 \%$ $\mathrm{RH}$.

TABLE 1: Sensing and kinetic parameters for all the devices extracted from the data.

\begin{tabular}{lccc}
\hline Parameters & QCM & PVP coated QCM & HKUST-1 coated QCM \\
\hline$\Delta f(\mathrm{~Hz})$ & 7 & 48 & 720 \\
$t_{\text {response }}(\mathrm{s})$ & 323 & 116 & 386 \\
$t_{\text {recovery }}(\mathrm{s})$ & 701 & 1676 & 1051 \\
$k_{d}\left(\mathrm{~s}^{-1}\right)$ & 0.0045 & 0.0051 & 0.0037 \\
$\theta$ & $43 \%$ & $61 \%$ & $69 \%$ \\
$E_{a}(\mathrm{~kJ} / \mathrm{mol})$ & 80.2 & 80.1 & 82 \\
\hline
\end{tabular}

\section{Conclusions}

We compared the performances of uncoated, PVP, and metal organic framework HKUST-1 coated quartz crystal

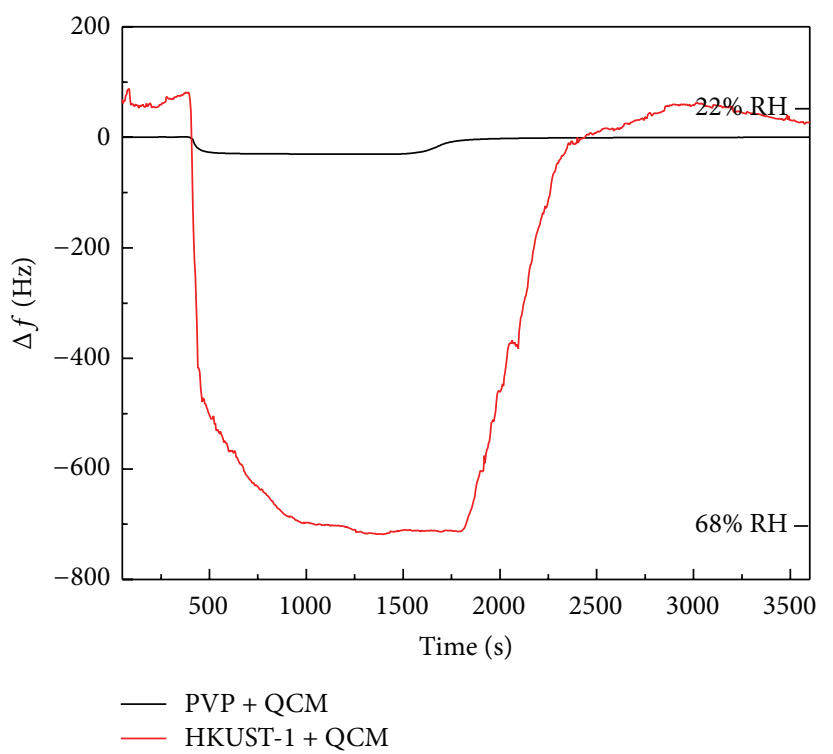

FIGURE 6: Frequency shift of the PVP and HKUST-1 coated QCM sensors by varying relative humidity from $22 \% \mathrm{RH}$ to $68 \% \mathrm{RH}$ to $22 \% \mathrm{RH}$ in the chamber.

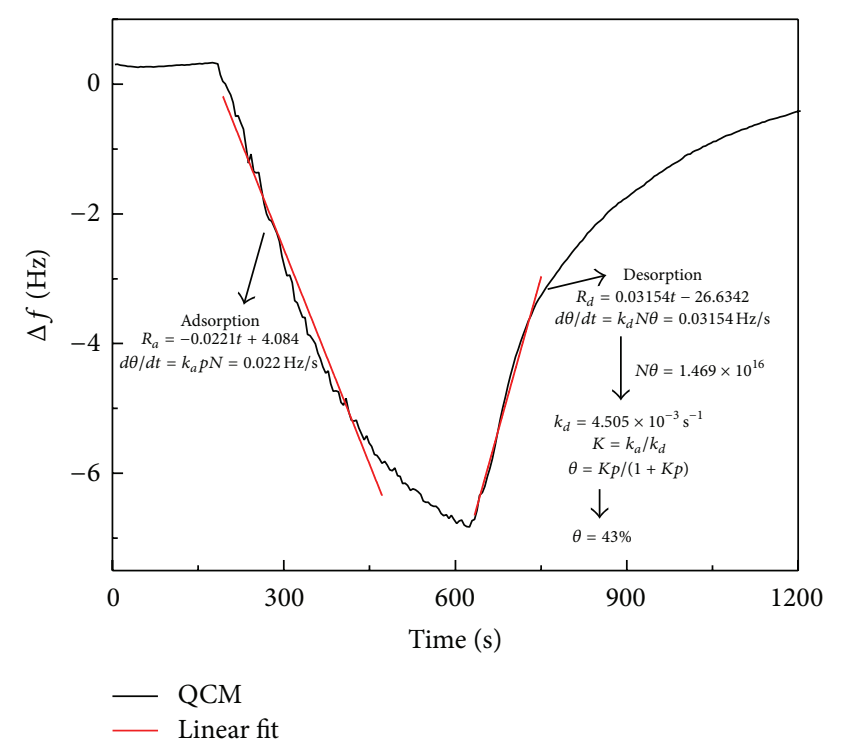

FIgURE 7: Adsorption and desorption cycle of uncoated QCM sensor for varying humidity from $22 \% \mathrm{RH}$ to $68 \%$. Kinetic parameters are extracted by a linear fit to adsorption and desorption curves.

microbalance as humidity sensors. The sensing properties, such as sensitivity, the response, and recovery times, are calculated from the experimental data and compared. The sensitivities of uncoated, PVP, and HKUST-1 coated QCM sensors are $7 \mathrm{~Hz}, 48 \mathrm{~Hz}$, and $720 \mathrm{~Hz}$ in the range of $22 \%-$ $69 \% \mathrm{RH}$, respectively. This shows that HKUST-1 coated QCM has high sensitivity because of its high adsorption energy and fractional coverage of the molecules on the surface. Kinetic parameters of adsorption and desorption of water molecules 
are extracted from the experimental data and reveal that HKUST-1 is a promising candidate for humidity detection.

\section{Competing Interests}

The authors declare that there is no conflict of interests regarding the publication of this paper.

\section{Acknowledgments}

The authors are thankful to Dr. Osama Shekhah and Professor Mohamed Eddaoudi for providing and helping in preparing HKUST-1. This research has been supported by KAUST.

\section{References}

[1] N. Yamazoe and Y. Shimizu, "Humidity sensors: principles and applications," Sensors and Actuators, vol. 10, no. 3-4, pp. 379398, 1986.

[2] U. Kang and K. D. Wise, "A high-speed capacitive humidity sensor with on-chip thermal reset," IEEE Transactions on Electron Devices, vol. 47, no. 4, pp. 702-710, 2000.

[3] A. E. Dessler and S. C. Sherwood, "A matter of humidity," Science, vol. 323, no. 5917, pp. 1020-1021, 2009.

[4] H. Nanto, S. Tsubakino, M. Habara et al., "A novel chemical sensor using $\mathrm{CH}_{3} \mathrm{Si}\left(\mathrm{OCH}_{3}\right)_{3}$ sol-gel thin film coated quartzresonator microbalance," Sensors and Actuators B: Chemical, vol. 34, no. 1-3, pp. 312-316, 1996.

[5] Y. Zhang, K. Yu, S. Ouyang et al., "Detection of humidity based on quartz crystal microbalance coated with $\mathrm{ZnO}$ nanostructure films," Physica B: Condensed Matter, vol. 368, no. 1-4, pp. 94-99, 2005.

[6] S. K. Vashist and P. Vashist, "Recent advances in quartz crystal microbalance-based sensors," Journal of Sensors, vol. 2011, Article ID 571405, 13 pages, 2011.

[7] M. T. S. R. Gomes, P. S. T. Nogueira, and J. A. B. P. Oliveira, "Quantification of $\mathrm{CO}_{2}, \mathrm{SO}_{2}, \mathrm{NH}_{3}$, and $\mathrm{H}_{2} \mathrm{~S}$ with a single coated piezoelectric quartz crystal," Sensors and Actuators B: Chemical, vol. 68 , no. 1-3, pp. 218-222, 2000.

[8] H. Nanto, N. Dougami, T. Mukai et al., "A smart gas sensor using polymer-film-coated quartz resonator microbalance," Sensors and Actuators B: Chemical, vol. 66, no. 1-3, pp. 16-18, 2000.

[9] K. Henkel, A. Oprea, I. Paloumpa, G. Appel, D. Schmeißer, and P. Kamieth, "Selective polypyrrole electrodes for quartz microbalances: $\mathrm{NO}_{2}$ and gas flux sensitivities," Sensors and Actuators, B: Chemical, vol. 76, no. 1-3, pp. 124-129, 2001.

[10] M. M. Ayad and N. L. Torad, "Alcohol vapours sensor based on thin polyaniline salt film and quartz crystal microbalance," Talanta, vol. 78, no. 4-5, pp. 1280-1285, 2009.

[11] H. Aizawa, S. Kurosawa, M. Tozuka, J.-W. Park, and K. Kobayashi, "Rapid detection of fibrinogen and fibrin degradation products using a smart QCM-sensor," Sensors and Actuators B: Chemical, vol. 101, no. 1-2, pp. 150-154, 2004.

[12] Y.-C. Liu, C.-M. Wang, K.-P. Hsiung, and C. Huang, "Evaluation and application of conducting polymer entrapment on quartz crystal microbalance in flow injection immunoassay," Biosensors and Bioelectronics, vol. 18, no. 7, pp. 937-942, 2003.

[13] V. N. Hung, T. Abe, P. N. Minh, and M. Esashi, "High-frequency one-chip multichannel quartz crystal microbalance fabricated by deep RIE," Sensors and Actuators A: Physical, vol. 108, no. 13, pp. 91-96, 2003.
[14] K. Galatsis, W. Qu, and W. Wlodarski, "Quartz crystal microbalance humidity sensor with porous electrodes," in Proceedings of the Optoelectronic and Microelectronic Materials Devices, pp. 373-375, Perth, Western Australia, 1999.

[15] H. Ito, R. Kakuma, R. Ohba, and K. Noda, "Development of a humidity sensor using quartz crystal microbalance," in Proceedings of the SICE 2003 Annual Conference, vol. 2, pp. 11751178, IEEE, Fukui, Japan, 2003.

[16] Y. Sakai, Y. Sadaoka, and M. Matsuguchi, "Humidity sensors based on polymer thin films," Sensors and Actuators B: Chemical, vol. 35, no. 1-3, pp. 85-90, 1996.

[17] P.-G. Su and W.-Y. Tsai, "Humidity sensing and electrical properties of a composite material of nano-sized $\mathrm{SiO}_{2}$ and poly(2-acrylamido-2-methylpropane sulfonate)," Sensors and Actuators, B: Chemical, vol. 100, no. 3, pp. 417-422, 2004.

[18] R.-J. Wu, Y.-L. Sun, C.-C. Lin, H.-W. Chen, and M. Chavali, "Composite of $\mathrm{TiO}_{2}$ nanowires and Nafion as humidity sensor material," Sensors and Actuators, B: Chemical, vol. 115, no. 1, pp. 198-204, 2006.

[19] O. M. Yaghi, M. O’Keeffe, N. W. Ockwig, H. K. Chae, M. Eddaoudi, and J. Kim, "Reticular synthesis and the design of new materials," Nature, vol. 423, no. 6941, pp. 705-714, 2003.

[20] S. Kitagawa, R. Kitaura, and S.-I. Noro, "Functional porous coordination polymers," Angewandte Chemie-International Edition, vol. 43, no. 18, pp. 2334-2375, 2004.

[21] U. Mueller, M. Schubert, F. Teich, H. Puetter, K. SchierleArndt, and J. Pastré, "Metal-organic frameworks-prospective industrial applications," Journal of Materials Chemistry, vol. 16, no. 7, pp. 626-636, 2006.

[22] J. Lee, O. K. Farha, J. Roberts, K. A. Scheidt, S. T. Nguyen, and J. T. Hupp, "Metal-organic framework materials as catalysts," Chemical Society Reviews, vol. 38, no. 5, pp. 1450-1459, 2009.

[23] X. Zhao, B. Xiao, A. J. Fletcher, K. M. Thomas, D. Bradshaw, and M. J. Rosseinsky, "Hysteretic adsorption and desorption of hydrogen by nanoporous metal-organic frameworks," Science, vol. 306, no. 5698, pp. 1012-1015, 2004.

[24] H. Yamagiwa, S. Sato, T. Fukawa et al., "Detection of volatile organic compounds by weight-detectable sensors coated with metal-organic frameworks," Scientific Reports, vol. 4, article 6247, 2014.

[25] T. Lee, Z. X. Liu, and H. L. Lee, "A biomimetic nose by microcrystals and oriented films of luminescent porous metalorganic frameworks," Crystal Growth and Design, vol. 11, no. 9, pp. 4146-4154, 2011.

[26] P. Á. Szilágyi, R. J. Westerwaal, R. van de Krol, H. Geerlings, and B. Dam, "Metal-organic framework thin films for protective coating of Pd-based optical hydrogen sensors," The Journal of Materials Chemistry C, vol. 1, no. 48, pp. 8146-8155, 2013.

[27] D. J. Wales, J. Grand, V. P. Ting et al., "Gas sensing using porous materials for automotive applications," Chemical Society Reviews, vol. 44, no. 13, pp. 4290-4321, 2015.

[28] S. Achmann, G. Hagen, J. Kita, I. M. Malkowsky, C. Kiener, and R. Moos, "Metal-organic frameworks for sensing applications in the gas phase," Sensors, vol. 9, no. 3, pp. 1574-1589, 2009.

[29] A. H. Khoshaman and B. Bahreyni, "Application of metal organic framework crystals for sensing of volatile organic gases," Sensors and Actuators B: Chemical, vol. 162, no. 1, pp. 114119, 2012.

[30] M. D. Allendorf, R. J. T. Houk, L. Andruszkiewicz et al., "Stress-induced chemical detection using flexible metal-organic frameworks," Journal of the American Chemical Society, vol. 130, no. 44, pp. 14404-14405, 2008. 
[31] I. Ellern, A. Venkatasubramanian, J. H. Lee et al., "Characterization of piezoresistive microcantilever sensors with metal organic frameworks for the detection of volatile organic compounds," ECS Transactions, vol. 50, no. 12, pp. 469-476, 2013.

[32] H. Li, M. Eddaoudi, M. O'Keeffe, and O. M. Yaghi, "Design and synthesis of an exceptionally stable and highly porous metal organic framework," Nature, vol. 402, no. 6759, pp. 276-279, 1999.

[33] P. Nugent, Y. Belmabkhout, S. D. Burd et al., "Porous materials with optimal adsorption thermodynamics and kinetics for $\mathrm{CO}_{2}$ separation," Nature, vol. 495, no. 7439, pp. 80-84, 2013.

[34] O. Shekhah, J. Liu, R. A. Fisher, and C. Wöll, "MOF thin films: existing and future applications," Chemical Society Reviews, vol. 44, no. 2, pp. 1081-1106, 2011.

[35] P. C. Xu, H. T. Yu, S. B. Guo, and X. X. Li, "Microgravimetric thermodynamic modeling for optimization of chemical sensing nanomaterials," Analytical Chemistry, vol. 86, no. 9, pp. 41784187, 2014.

[36] S. Guo, P. Xu, H. Yu, Z. Cheng, and X. Li, "Synergistic improvement of gas sensing performance by microgravimetrically extracted kinetic/thermodynamic parameters," Analytica Chimica Acta, vol. 863, no. 1, pp. 49-58, 2015.

[37] L. A. Pinnaduwage, T. Thundat, A. Gehl, S. D. Wilson, D. L. Hedden, and R. T. Lareau, "Desorption characteristics of uncoated silicon microcantilever surfaces for explosive and common nonexplosive vapors," Ultramicroscopy, vol. 100, no. 34, pp. 211-216, 2004. 


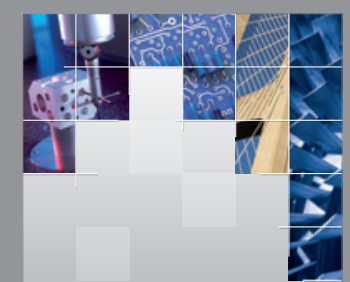

\section{Enfincering}
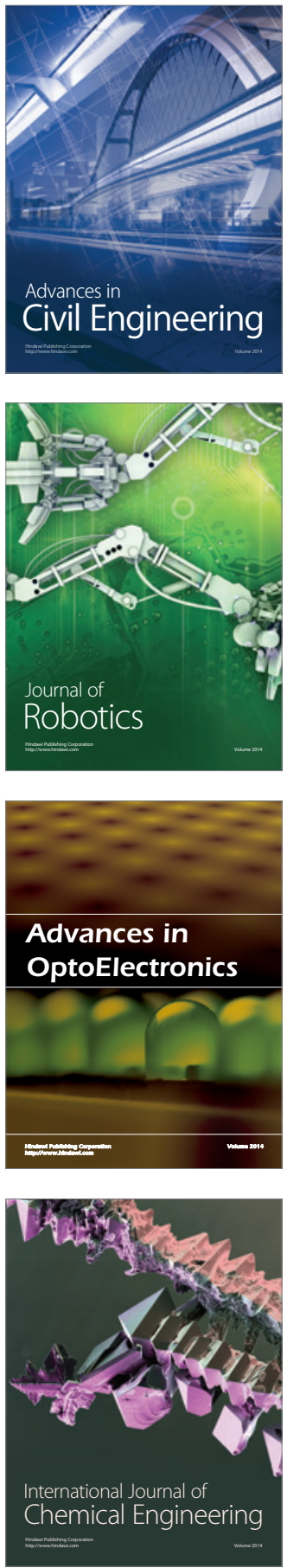

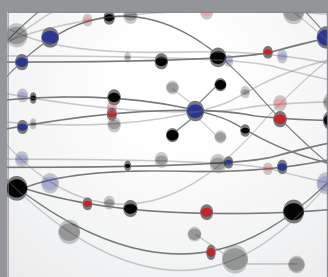

The Scientific World Journal

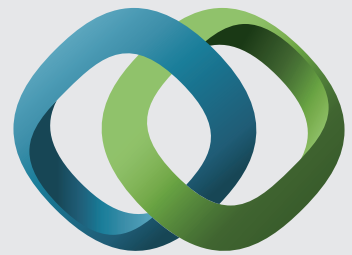

\section{Hindawi}

Submit your manuscripts at

http://www.hindawi.com
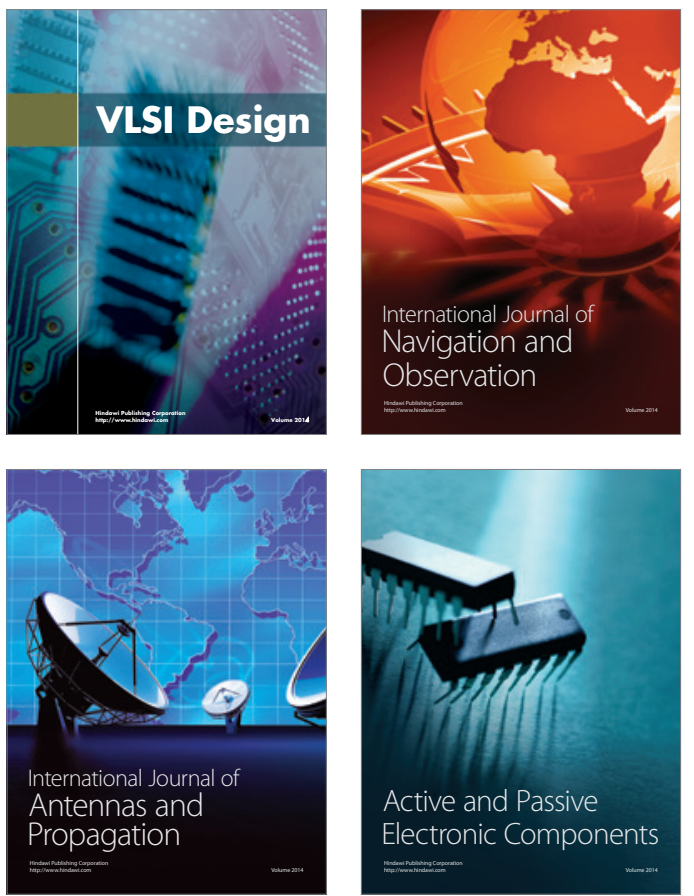
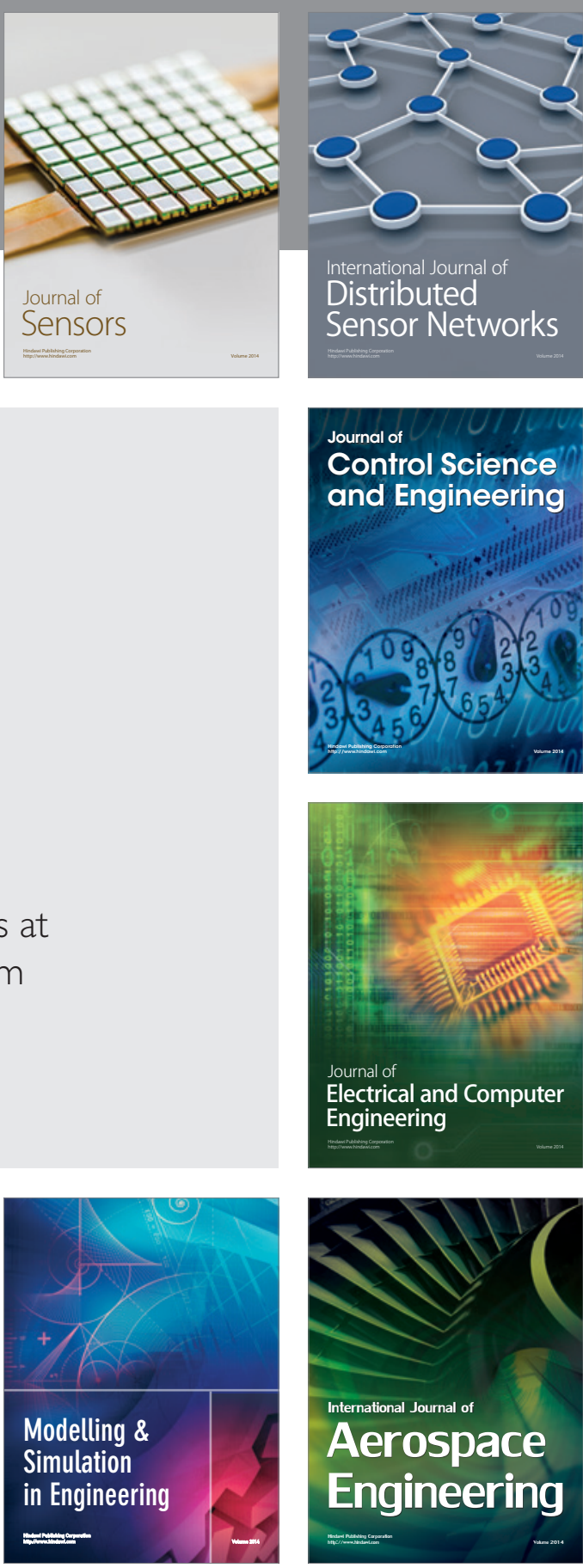

International Journal of

Distributed

Sensor Networks

Journal of

Control Science

and Engineering
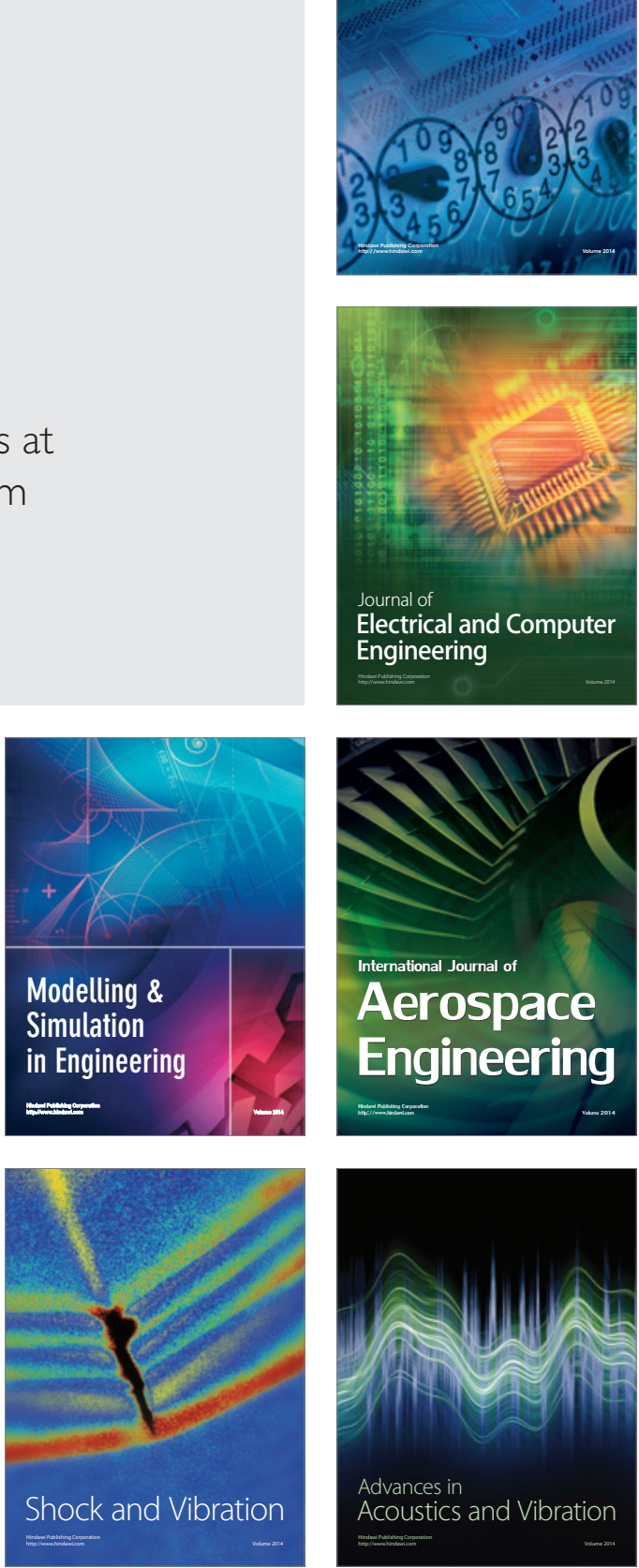